\title{
EFFECTS OF REGIONALIZED TRADE RESTRICTIONS ON QUANTITY EXPORTED DURING A HIGHLY PATHOGENIC AVIAN INFLUENZA EVENT
}

\author{
JADA M. THOMPSON* \\ Department of Agricultural and Resource Economics, University of Tennessee, Knoxville, Tennessee
}

\begin{abstract}
From December 2014 to June 2015, U.S. poultry was affected by highly pathogenic avian influenza that led to destruction of 48 million birds and losses in international trade. During the event, 45 countries placed trade restrictions on U.S. poultry exports, varying from regionalized to national poultry restrictions. Using a gravity model of trade, the effects on quantity traded is estimated for poultry exports at the aggregated and disaggregated commodity level to understand product flows during an event. Results indicate U.S. poultry exports benefit from countries willing to apply limited trade restrictions, and the trade impact varies across disaggregated commodities.
\end{abstract}

Keywords. Avian influenza, gravity model, poultry, trade restrictions

JEL Classifications. Q17, F14

\section{Introduction}

Animal agriculture can be affected by highly pathogenic disease events such as foot-and-mouth disease (FMD) in cattle and swine or highly pathogenic avian influenza (HPAI) in poultry. The impacts of these diseases can be prolific across the supply chain, affecting producers, processors, consumers, and trading partners (Huang, Hagerman, and Bessler, 2016; Paarlberg et al., 2009; Pendell et al., 2007). The total impact of a disease event can be costly and detrimental to animal agriculture in the affected country. Producers can be affected by the reduction in animal inventories because of disease or disease management strategies. In response to reduced domestic supplies, processors may have processing shortages for some or all products. Prolonged supply shocks at the

*Corresponding author's e-mail: jthom207@utk.edu

The author would like to sincerely thank Ann Hillberg Seitzinger for recording the 2015 trade restrictions and for her helpful comments and suggestions. This material is based on work supported by the U.S. Department of Agriculture (USDA) under Cooperative Agreement Number 16-9220-0455-CA. The views and conclusions in this document are those of the authors and should not be interpreted as necessarily representing the official polices, either expressed or implied, of the USDA. 
producer level can lead to increased prices to consumers. These price increases from supply shortages may be partially offset by the impacts of trade embargoes. Trading partners may restrict products from a country known to be infected with an infectious disease, potentially affecting the quantity and composition of products exported. This work analyzes these changes in the quantity of poultry traded as a result of importer trade restriction to show how the geographic extent of a trade restriction affects trade heterogeneously across poultry products.

An importing country's decision to restrict products from a country or region because of food safety and biosecurity concerns is a multifaceted process. Approaching the decision to impose a trade restriction in general terms, importing countries must first decide if trade restrictions are necessary. Second, if restrictions are imposed, importing countries decide which products should be included in the restrictions. Finally, importing countries must decide the geographic extent of the restrictions, which can mitigate some of the trade interruptions depending on the restricted area. The importing country may choose to adopt regionalized trade restrictions, for which the infected exporting country can be separated into disease-free and affected zones. Under this strategy, a specific region is considered to be under the export restriction, and the rest of the country (i.e., the disease-free zone) is free to trade (Seitzinger and Paarlberg, 2016).

The decision to restrict a product category's trade can lead to a change in the composition of products traded, potentially leading to increased demand for products excluded from the trade restriction. The potential increase in demand compensates for the loss of restricted products or shifting of imports to alternative export markets to meet the importing country's demand. Some importing countries may benefit from reduced prices and supply available during the disease event. By analyzing changes in export composition and the effects of trade restrictions during a disease event, the effects of importing country trade responses can be estimated.

From December 2014 to June 2015, U.S. poultry experienced an HPAI event that led to the destruction of 49.6 million birds, increases in consumer prices, losses in international trade, and costs of response of more than $\$ 950$ million to U.S. taxpayers (Thompson and Pendell, 2016; U.S. Department of Agriculture, Animal and Plant Health Inspection Service [USDA-APHIS], 2015a, 2016). The disease event affected predominantly egg and turkey production-67\% were layers, $12 \%$ were pullets, and $16 \%$ were turkeys (USDA-APHIS, 2015b). Several U.S. trade partners chose to impose trade restrictions on poultry, not limited to layers and turkeys. The trade restrictions imposed were extended to many, if not all, poultry product types. During the disease event, 44 countries placed some form of trade restriction on U.S. poultry exports, varying from regionalized, product-type-specific restrictions to total U.S. poultry embargoes. Typically, trade restrictions are unknown, or unrecorded, and so cannot directly contribute to the economic analysis of disease impacts on trade. However, for the 20142015 HPAI event, these trade restrictions were recorded. Using these trade restrictions, this work evaluates the effect importing country trade restrictions 
had on U.S. export trade quantities and product composition during the 20142015 HPAI event in U.S. poultry. Quantifying the changes in poultry trade and the effects of importing country trade restrictions on U.S. poultry exports provides a rich analysis of trade restriction types and their effect on quantity traded.

\section{Background}

Trade is an important component of the U.S. poultry industry, in which nearly 1 in 5 pounds produced is marked for international markets. The United States exported $19 \%$ of broiler production, $14 \%$ of turkey production, and $5 \%$ of egg production in 2014, prior to the HPAI event in U.S. poultry (USDA, Office of the Chief Economist, 2016). Disease events can have negative impacts on domestic markets, which can extend to the value and quantity of product traded (Huang et al.2016). Although there can be trade creation with countries willing to accept product during a disease event, this does not always compensate for the reduction in supply or changes in export revenue. Export revenue recovery can be a lengthy process even after a country is declared disease free, creating additional economic effects of a disease event (Johnson et al., 2015).

The effects of a contagious animal disease have been studied in the literature for various diseases such as FMD or bovine spongiform encephalopathy (BSE). The impacts of a disease event often result in trade disruptions in both the importing and exporting countries. Uncertainty surrounding the duration of a trade disruption can intensify the negative effects, leading to market disrupting producer behavior (Ruhl, 2011). Paarlberg and Lee (1998) assessed the risk of disease spread through imports as they are tied to tariff trade barriers, showing that as the risk or expected losses rise, trade barriers become prohibitive. Wilson and Antón (2006) also studied disease risk and its effects on markets, including international trade, showing these effects can be reduced by practices that mitigate disease risk. Costa, Bessler, and Rosson (2015) analyzed the impacts of the 2005 FMD event in Brazil, showing domestic prices suffered until the removal of the trade restrictions imposed on Brazilian beef. Each of these studies provided insights into the negative market effects that contagious animal disease can have through trade restrictions.

For poultry, theoretical, regionalized trade impacts have been studied in the literature. Paarlberg, Seitzinger, and Lee (2007) modeled the implications of regionalized trade restrictions because of a hypothetical HPAI event in the United States. Their findings showed that regionalization can reduce the negative economic impacts of an HPAI event in U.S. poultry. Johnson et al. (2014) modeled the effects of state-level regionalization in the face of an event of HPAI in Texas poultry, showing that regionalization by trading partners reduced the loss in U.S. poultry exports in the first quarter from a $94 \%$ reduction of exports to $29 \%$. Although the affected region isolation can cause increased economic impacts 
locally, the cumulative negative effects on the exporter are reduced by importing countries adopting a regionalized trading strategy.

The aim of this work is to estimate the impact importing country trade restrictions have on quantity traded. The data available for this analysis are rich in depth, providing a multilevel analysis. Trade restriction effects can be estimated across all commodities or heterogeneously at a commodityspecific level, providing general implications and specific commodity effects. The nature of the trade restriction-whether it is a national-, state-, or county-level restriction or a general aggregation across all of these-can provide a deeper understanding of the impacts of a trade restriction during a disease event. To provide a robust and comprehensive analysis of the U.S. HPAI event, this work is separated into four analyses and effectively four models: (1) average trade effects by general trade restrictions; (2) heterogeneous, commodity-specific trade effects by general trade restrictions; (3) average trade effects by types of trade restrictions; and (4) heterogeneous, commodity-specific trade effects by types of trade restrictions. Each analysis will provide a different facet and explanation for the changes in trade because of importing country trade decisions during the 2014-2015 HPAI event in the United States.

\section{Methodology}

The gravity model has been used heavily in the trade literature to econometrically explain bilateral trade and factors that contribute to trade (Anderson, 2010; Baltagi, Egger, and Pfaffermayr, 2014; Chaney, 2013; Koo, Karemera, and Taylor, 1994; Sun and Reed, 2010). To study the impacts of known trade restrictions, a general gravity trade model will be used (Anderson and van Wincoop, 2003; Vollrath and Hallahan, 2011). The gravity model was originally proposed by Isard (1954) and Tinbergen (1962), which bases trade relationships on Sir Isaac Newton's general gravity equation that defines gravity as directionally proportional to the mass of two objects and indirectly proportional to the distance between the objects. Bergstrand (1985) provided microeconomic theoretical foundations for the model. The basic gravity trade specification can be expressed as follows:

$$
Y_{i j}=C \frac{M_{i}^{\beta_{1}} M_{j}^{\beta_{2}}}{d_{i j}^{\beta_{3}}},
$$

where $Y_{i j}$ represents the quantity traded between $i$ and $j, C$ represents a proportional constant term, $M$ represents the mass term of both the $i$ and $j$ countries (typically expressed using country gross domestic product [GDP] or population weighted GDP), $d_{i j}$ is the distance from $i$ to $j, \beta_{1}$ is the trade flow creation parameter, $\beta_{2}$ is the trade flow attraction parameter, and $\beta_{3}$ is the trade flow resistance parameter. Typically, the gravity model is logged to facilitate estimation. 
The model has since been expanded to include additional parameters to indicate additional trade factors (Martínez-Zarzoso and Nowak-Lehmann, 2003).

To account for multilateral resistance between trading partners, a general form of the gravity model was developed and has been used in the literature (Anderson and van Wincoop, 2003; Baier and Bergstrand, 2007; Vollrath and Hallahan, 2011). Although the traditional gravity model includes variables that can be predictive of trade, it may not fully capture the unique relationship between partners, or it may fail to fully capture the heterogeneity between partners. The general form conceptualizes the nuances of trade into partner-specific binary variables that capture the heterogeneous variation around the bilateral relationships, accounting for cultural, political, and macroeconomic effects that are typically included or approximated in the traditional gravity model. Partnerspecific binary variables take the place of defining population, GDP, distance, or other dyadic determinants-common language, common colonizer, and other common indicator variables. Anderson and van Wincoop (2003) propose using time-by-partner binary variables; however, the data needs for that specification can become prohibitive. Alternative time-partner specification can be used to ensure model identification. For this research, time period-specific variables are used, which do not perfectly capture the time-by-partner variation but do allow for some variation to be modeled.

To model the first objective-average effects of a general trade restriction-a general gravity model is specified as follows:

$$
\begin{aligned}
\ln \left(\mathrm{Y}_{i k t}\right)= & \beta_{0}+\beta_{1} \text { Ban }_{i k t}+\gamma_{1} \text { Importer }_{i k t}+\gamma_{2} \text { Commodity }_{i k t} \\
& +\sum_{t} \gamma_{3 t} \text { Period }_{t}+\varepsilon_{i t},
\end{aligned}
$$

where $Y$ represents quantity traded; $B a n_{i k t}=1$ if importing country $i$ in period $t$ trading product $k$ placed a trade restriction, and 0 otherwise; Importer $_{i k t}=1$ for importing country $i$ in period $t$ trading product $k$, and 0 otherwise; Commodity ${ }_{i k t}$ $=1$ for commodity $k$ in period $t$ traded by importing country $i$, and 0 otherwise; Perio $_{t}$ represents a series of time binary variables; $\beta$ and $\gamma$ are coefficients on represented variables representing proportional trade flow creation or restriction; and $\varepsilon_{i t}$ is the composite error term including the undefined individual effects. Modeling general commodity restrictions provides insights into the response of trade when an importing country chooses to apply any type of trade restriction.

To model the second objective-heterogeneous, commodity-specific effects of general trade restriction-equation (2) is extended to explicitly define trade restrictions by commodity and is presented in equation (3):

$$
\begin{aligned}
\ln \left(\mathrm{Y}_{i k t}\right)= & \beta_{0}+\sum_{k} \beta_{k} \text { CommodityBan }_{i k t}+\gamma_{1} \text { Importer }_{i k t}+\gamma_{2} \text { Commodity }_{i k t} \\
& +\sum_{t} \gamma_{3 t} \text { Period }_{t}+\varepsilon_{i t}
\end{aligned}
$$


where CommodityBan $=1$ if importing country $i$ in period $t$ trading product $k$ placed a trade restriction on product $k$, and 0 otherwise; and $\beta_{k}$ represents the $k$ coefficients for the product-specific restriction variables. All other variables and parameters are defined previously. Using explicit commodity-specific trade restrictions provides a unique analysis of how trade restrictions on average affect individual poultry commodities, as opposed to the more general modeling from equation (2).

Although the first two objectives focused on the average implications of an aggregation of all restriction types, the following two models assess how the varying types of trade restrictions affect trade flows. To model the third objective-average effects by trade restriction type-previous equations are modified so that instead of a general trade restriction variable, individual variables are included for each trade restriction type (equation 4):

$$
\begin{aligned}
\ln \left(Y_{i k t}\right)= & \beta_{0}+\beta_{1} \text { National Ban }_{i k t}+\beta_{2} \text { State Ban }_{i k t}+\beta_{3} \text { County Ban }_{i k t} \\
& +\gamma_{1} \text { Importer }_{i k t}+\gamma_{2} \text { Commodity }_{i k t}+\sum_{t} \gamma_{3 t} \text { Period }_{t}+\varepsilon_{i j t},
\end{aligned}
$$

where NationalBan $n_{i k t}=1$ if importing country $i$ in period $t$ trading product $k$ placed a national-level trade restriction, and 0 otherwise; StateBan $n_{i k t}=1$ if importing country $i$ in period $t$ trading product $k$ placed a state-level trade restriction, and 0 otherwise; CountyBan $n_{i k t}=1$ if importing country $i$ in period $t$ trading product $k$ placed a county-level trade restriction, and 0 otherwise; and all other variables and parameters are defined previously.

To model the fourth objective-heterogeneous, commodity-specific effects by trade restriction type-equation (4) is expanded to commodity-specific restriction types (equation 5):

$$
\begin{aligned}
\ln \left(Y_{i k t}\right)= & \beta_{0}+\sum_{k} \beta_{k}^{1} \text { CommodityNationalBan }_{i k t}+\sum_{k} \beta_{k}^{2} \text { CommodityState Ban }_{i k t} \\
& +\sum_{k} \beta_{k}^{3} \text { Commodity County Ban }_{i k t}+\gamma_{1}{\text { Importe } r_{i k t}+\gamma_{2} \text { Commodity }_{i k t}} \\
& +\sum_{t} \gamma_{3} \text { Period }_{t}+\varepsilon_{i j t},
\end{aligned}
$$

where CommodityNationalBan ${ }_{i k t}=1$ if importing country $i$ in period $t$ trading product $k$ placed a national-level trade restriction on product $k$, and 0 otherwise; CommodityStateBan ${ }_{i k t}=1$ if importing country $i$ in period $t$ trading product $k$ placed a state-level trade restriction on product $k$, and 0 otherwise; CommodityCountyBan $n_{i k t}=1$ if importing country $i$ in period $t$ trading product $k$ placed a county-level trade restriction on product $k$, and 0 otherwise; $\beta_{k}^{1,2,3}$ represents the $k$ coefficients for the product-specific national-, state-, and county-level restrictions; and all other variables and parameters are 
defined previously. This final model provides the implications of the type of restriction by commodity, assessing if individual commodity trade response varies by the type of restriction placed by the importing partner.

The multilevel panel data are tested using a Breusch-Pagan Lagrangian multiplier test for random effects (Breusch and Pagan, 1980). A Hausman specification test is used to test whether the individual effects are correlated with the error term, motivating a fixed effects modeling framework (Hausman, 1978). The models fail to meet the asymptotic assumptions of the Hausman test, and as motivated by literature, the random effects model would not be appropriate in the presence of fixed effects (Baltagi, Bresson, and Pirotte, 2003). In order to estimate equations (2) through (5), a Hausman-Taylor (HT) estimator will be used (Hausman and Taylor, 1981), which will capture both the between and within variation in the data and overcome the limitations of the fixed effects approach given individual effects and time invariant variables of interest. Briefly, the HT model is estimated as a multistep feasible generalized least squares approach, which separates variables as either exogenous or endogenous, as well as time variant or invariant. The estimator internally uses the exogenous time variant variables as an instrumental variable for the time invariant endogenous variable(s). The HT estimator makes independent and identically distributed assumptions regarding the unobserved individual effects and the idiosyncratic error term. This model continues to be a useful alternative method for analyzing multilevel panel data (Brent, 2017; Egger and Pfaffermayr, 2004; Serlenga and Shin, 2007). Four HT models will be estimated corresponding to the four equations and the four objectives of this work, and the standard errors will be calculated as conventional panel standard errors that rely on asymptotic theory. ${ }^{1}$

As this work uses semilogarithmic models with binary variables, a brief discussion is in order to describe how the presented elasticities will be calculated. For a continuous variable, the coefficient on the variable of interest can be multiplied by 100 to derive the elasticity, or the percentage change in the dependent variable for a small change in the independent variable. However, with a binary variable, this multiplier is not appropriate for large changes and can lead to misleading and erroneous results. ${ }^{2}$ The appropriate calculation was presented by Halvorsen and Palmquist (1980) and is presented in equation (6), where $\beta_{i}$ is the calculated coefficient on the binary variable.

$$
100 \times\left(\exp ^{\beta_{i}}-1\right)
$$

1 Although there was work in estimating standard errors that correct for potential serial autocorrelation, there was not a discernable pattern in the resulting errors, and this approach often led to less efficient estimations. The conventional standard errors will be presented so that the variable significance is conservative as the presence of serial correlation would inflate the standard errors.

2 For very small changes, the method used for continuous variables approximates the actual changes for a binary variable such that researchers may treat the binary variable as continuous (Halvorsen and Palmquist, 1980). 
For this work, the elasticities will be calculated with this equation, and the elasticities rather than the coefficients will be presented for clarity in interpretation.

\section{Data}

Multilevel data are compiled to support this work, focusing on the implications of export trade restrictions on U.S. poultry trade. Monthly trade data from 2010 to 2016 are collected from IHS Markit's Global Trade Atlas (GTA) database (https://www.ihs.com/products/maritime-global-trade-atlas.html) for every U.S. poultry trading partner for poultry products at the six-digit harmonized code level. Trade restrictions were recorded during the 20142015 U.S. HPAI event by commodity and by importing country including the nature of the restrictions-whether they were national-, state-, or countylevel restrictions-and the products affected as reported by USDA's Food Safety and Inspection Service. These were collected weekly prior to the website (https://www.fsis.usda.gov/wps/portal/fsis/topics/international-affairs/ exporting-products/export-library-requirements-by-country) refreshing to provide a complete set of restrictions during the event. The reports included the reporting country; date the restrictions were reported to the USDA; an ending date or termination date, if applicable; the restriction's geographic scope; and the products or groups of commodities included in the restrictions. Over the course of the HPAI event, 17 of the 32 countries included in this analysis applied a restriction, of which 3 applied national-level restrictions, 13 applied state-level restrictions, and 6 applied county-level restrictions. These are included in the various models as indicator variables.

Every product and trade relationship is important to the U.S. poultry industry, but not every importing country or product has a consistent trade relationship over time. To determine the countries to include in the analysis, a 5-year, diseasefree period (2010-2014) of trade was assessed. This disease-free period represents an interval of time in poultry trade that was not affected by disease events and should represent normal trade flows in the absence of a trade disrupting event. An Olympic average, ${ }^{3}$ a mean calculated after excluding the extrema from a numerical series, of trade over the 5 -year period show the countries that, on average, account for at least half of a percent of trade to be included in the analysis. The countries included account for $87 \%$ of poultry exports from the United States, which limits the analysis to importing countries with a minimally consistent poultry trade relationship with the United States. This also removes trading partners that are not internationally recognized such as "International Waters."

3 The Olympic average for country $i$ can be represented by: $\bar{Q}^{i}=$ $\frac{1}{T-2}\left[\left(\sum_{t=1}^{T} \sum_{k} Q_{k, t}^{i}\right)-\max _{t \in T} \sum_{k} Q_{k, t}^{i}-\min _{t \in T} \sum_{k} Q_{k, t}^{i}\right]$, where $Q^{i}$ is the quantity traded, $t$ is the time period, $T$ is the total number of monthly periods, and $k$ represents the individual commodities. 
Table 1. U.S. Poultry Trading Partners Representing at Least $0.5 \%$ of U.S. Trade and Importing Country Proportion of Trade Represented by U.S. Exports for the Period 2010-2014

\begin{tabular}{|c|c|c|}
\hline Country & $\begin{array}{l}\text { Importing Country } \\
\text { Share of U.S. Poultry } \\
\text { Exports }(\%)\end{array}$ & $\begin{array}{l}\text { U.S. Share of } \\
\text { Importing Country } \\
\text { Poultry Trade }^{\mathrm{a}}(\%)\end{array}$ \\
\hline Mexico & 18.5 & 94.2 \\
\hline Hong Kong & 9.1 & 28.0 \\
\hline Canada & 6.1 & 71.0 \\
\hline Russiab $^{b}$ & 5.7 & 24.3 \\
\hline China & 5.7 & 47.9 \\
\hline Angola & 4.4 & 32.5 \\
\hline Cuba & 3.1 & 42.5 \\
\hline Taiwan & 2.9 & 99.3 \\
\hline Iraq & 2.1 & 13.8 \\
\hline Georgia & 2.1 & $\mathrm{~N} / \mathrm{A}^{\mathrm{c}}$ \\
\hline Philippines & 1.9 & 54.4 \\
\hline Indonesia & 1.8 & $\mathrm{~N} / \mathrm{A}^{\mathrm{c}}$ \\
\hline United Arab Emirates & 1.8 & 17.5 \\
\hline Guatemala & 1.8 & 89.7 \\
\hline Korea, South & 1.7 & 32.8 \\
\hline Vietnam & 1.7 & 10.0 \\
\hline Lithuania & 1.6 & $\mathrm{~N} / \mathrm{A}^{\mathrm{c}}$ \\
\hline Chile & 1.5 & 78.7 \\
\hline Haiti & 1.4 & 47.7 \\
\hline Japan & 1.3 & 5.0 \\
\hline Turkey & 1.2 & $\mathrm{~N} / \mathrm{A}^{\mathrm{c}}$ \\
\hline Kazakhstan & 1.1 & $\mathrm{~N} / \mathrm{A}^{\mathrm{c}}$ \\
\hline Ghana & 1.0 & 30.4 \\
\hline Jamaica & 0.9 & 44.0 \\
\hline Congo & 0.9 & 33.4 \\
\hline Dominican Republic & 0.9 & 48.3 \\
\hline Singapore & 0.8 & 38.8 \\
\hline Ukraine & 0.8 & 14.1 \\
\hline Colombia & 0.8 & 68.4 \\
\hline Democratic Republic of the Congo & 0.7 & 34.5 \\
\hline Afghanistan & 0.7 & 14.7 \\
\hline Trinidad and Tobago & 0.6 & 43.4 \\
\hline Gabon & 0.5 & 34.2 \\
\hline Total & 87.1 & \\
\hline
\end{tabular}

${ }^{a}$ For countries not reporting to the Global Trade Atlas (GTA) database, these are approximate import quantities reported as exports from countries reporting to GTA.

${ }^{\mathrm{b}}$ Russia is excluded from this analysis. It banned U.S. poultry prior to the study period.

${ }^{\mathrm{c}}$ These values could not be appropriately approximated because of data limitations.

All countries included in the analysis are listed in Table 1 , as well as representative market shares for the period 2010 to 2014. The only exception is Russia, a historically important poultry export market; it is not included in this analysis as it implemented bilateral trade restrictions on U.S. poultry products prior to 
the HPAI event and thus would not reflect changes as a result of disease. In total, there are 32 countries included in the analysis. The data used in the analysis are exports reported to all trade partners, but additional data were collected to understand the relative importance of U.S. poultry meat in importing markets. Import market data not reported to the GTA by the trade partners are accessible through proxy data, or the sum of the reported exports to the importing country. These import quantities are expected to be conservative in nature, as they may be missing trading partners not reported to the GTA, but the data do provide an indicator of trade for partners that would otherwise be excluded.

In Table 1, the importing country share of U.S. poultry exports represents the relative market share of the importing country for total U.S. poultry export quantities. The U.S. share of importing country poultry trade denotes the relative market share of U.S. poultry in the importing country's market. For example, on average Mexico is the destination for $18.5 \%$ of total U.S. poultry exports, and U.S. poultry meat and products account for $94.2 \%$ of all Mexican poultry imports. Understanding the relative importance of both the import and export market provides context for the changes in trade that may occur by country. Although this work does not analyze country-specific trade implications, they are an important aspect in estimating the magnitude of trade quantity changes because of the HPAI event in U.S. poultry.

Similarly, commodities are limited to those poultry products that consistently represent a minimal export magnitude for the United States. Using an Olympic average of the 5-year disease-free period (2010-2014) prior to the HPAI event, commodities that represented at least $1 \%$ of trade from the United States are included in this analysis. The included commodities represent $90 \%$ of all poultry exports sourced from the United States over that 3-year period. Although these limitations do restrict trade partners and commodities from the analysis, they represent the partners and commodities with a consistent, minimal level of trade, consequently reducing spurious relationships and ensuring a sufficient number of observations to ascertain the effects of trade restrictions as a result of the HPAI outbreak in the United States. A full description of these commodities is presented in Table 2, as well as the short name of each commodity that will be used in the discussion for this work.

In gravity models, zero trade flows can create modeling issues. Zero trade flows can be separated into zero trade recorded in the data and zeros included to balance the panel by replacing missing trade reports. Typically, the latter are considered data skewing as they may or may not reflect the actual state of bilateral trade because they are replacing a missing value, which creates errors in the disturbance term (Anderson, 2010). Researchers have looked to alternate estimators to address the issues created by efforts to balance data with zero trade flows, resulting in the creation of trade relationships when products were never traded (Burger, van Oort, and Linders, 2009). For this analysis, relationships that have historically not existed were not included (i.e., the panel 
Table 2. Commodities Included in Analysis Representing 90\% of All U.S. Poultry Trade for Disease-Free Period (2010-2014) and at Least $1 \%$ of U.S. Trade

\begin{tabular}{|c|c|c|c|}
\hline Full Commodity Description & Short Commodity Name & Harmonized Code & $\begin{array}{l}\text { Percent of } \\
\text { Total U.S. } \\
\text { Poultry Trade }\end{array}$ \\
\hline Leg quarters of chickens, frozen & Frozen chicken leg quarters & 207140010 & 40.10 \\
\hline $\begin{array}{l}\text { Meat of chickens, frozen, not } \\
\text { elsewhere specified or } \\
\text { indicated }\end{array}$ & Frozen chicken meat & 207140090 & 11.30 \\
\hline $\begin{array}{l}\text { Meat and edible offal of } \\
\text { chickens, fresh or chilled }\end{array}$ & Fresh chicken meat/edible offal & 207130000 & 10.40 \\
\hline Feet (paws) of chickens, frozen & Frozen chicken paws & 207140045 & 7.70 \\
\hline $\begin{array}{l}\text { Legs of chickens, frozen, not } \\
\text { elsewhere specified or } \\
\text { indicated }\end{array}$ & Frozen chicken legs & 207140025 & 5.30 \\
\hline $\begin{array}{l}\text { Meat and edible offal of } \\
\text { turkeys, fresh or chilled }\end{array}$ & Fresh turkey meat/edible offal & 207260000 & 2.50 \\
\hline Feather meal & Feather meal & 505902020 & 2.40 \\
\hline $\begin{array}{l}\text { Wings tips, parts thereof of } \\
\text { chickens, frozen }\end{array}$ & Frozen chicken wing tips & 207140030 & 2.40 \\
\hline $\begin{array}{l}\text { Gallus domesticus fresh eggs, } \\
\text { not elsewhere specified or } \\
\text { indicated }\end{array}$ & Fresh chicken eggs & 407210000 & 1.90 \\
\hline $\begin{array}{l}\text { Chicken, } \mathrm{Lt}=185 \mathrm{~g} \text {, breeding } \\
\text { stock, meat-type, live }\end{array}$ & Live chicken-breeding stock & 105110020 & 1.70 \\
\hline $\begin{array}{l}\text { Other prepared/preserved } \\
\text { chicken meat, paste of } \\
\text { chicken, miscellaneous }\end{array}$ & Prepared/preserved chicken meat & 1602320035 & 1.30 \\
\hline $\begin{array}{l}\text { Meat of turkeys, frozen, not } \\
\text { elsewhere specified or } \\
\text { indicated }\end{array}$ & Frozen turkey meat & 207270090 & 1.10 \\
\hline $\begin{array}{l}\text { Chickens, whole, young, fresh } \\
\text { or chilled }\end{array}$ & Fresh whole chicken & 207110020 & 1.00 \\
\hline $\begin{array}{l}\text { Legs of turkeys, with bone, } \\
\text { frozen }\end{array}$ & Frozen turkey legs & 207270010 & 1.00 \\
\hline
\end{tabular}

was not balanced with zeros in order to preserve reported trade values). Because of the restrictions placed on partners and products, there were very few true zero trade relationships (i.e., a partner reduced all trade to zero units, which can be because of transportation and reporting lags). For these few true zero observations $(0.42 \%$ of all trade flows), the zeros were replaced with an arbitrary small number $(0.0001)$ to allow for their inclusion in the analysis, but not to create any biases in the results.

Descriptive statistics for model variables are included in Table 3. Exhaustive partner-specific and time-specific variables are excluded from the table but are available from the authors. 
Table 3. Select Descriptive Statistics for Monthly Panel Data, January 2010-July 2016

\begin{tabular}{lllll}
\hline \hline & & Standard & & \\
Variable & Mean & Deviation & Minimum & Maximum \\
\hline Quantity (units) & $1,627,165$ & $3,997,738$ & 0 & $91,000,000$ \\
Observations & 13,159 & & & \\
Trading partners & 32 & & & \\
Trading-commodity pairs & 334 & & & \\
Time (months) & 79 & & & \\
Percentage of affected trade observations for binary restriction variables & & \\
\hline & Any Trade & National & State & County \\
& Restriction $(\%)$ & Restriction $(\%)$ & Restriction $(\%)$ & Restriction $(\%)$ \\
\hline Total poultry trade & 3.72 & 0.91 & 2.38 & 1.12 \\
Frozen chicken leg quarters & 0.56 & 0.14 & 0.33 & 0.17 \\
Frozen chicken meat & 0.47 & 0.08 & 0.33 & 0.16 \\
Fresh chicken meat/edible offal & 0.13 & 0.00 & 0.11 & 0.07 \\
Frozen chicken paws & 0.25 & 0.12 & 0.11 & 0.06 \\
Frozen chicken legs & 0.53 & 0.10 & 0.37 & 0.16 \\
Fresh turkey meat/edible offal & 0.11 & 0.00 & 0.08 & 0.06 \\
Feather meal & 0.07 & 0.01 & 0.06 & 0.03 \\
Frozen chicken wing tips & 0.08 & 0.02 & 0.05 & 0.01 \\
Fresh chicken eggs & 0.06 & 0.02 & 0.04 & 0.03 \\
Live chicken-breeding stock & 0.31 & 0.19 & 0.10 & 0.06 \\
Prepared/preserved chicken meat & 0.07 & 0.00 & 0.05 & 0.04 \\
Frozen turkey meat & 0.34 & 0.05 & 0.25 & 0.13 \\
Fresh whole chicken & 0.27 & 0.02 & 0.22 & 0.10 \\
Frozen turkey legs & 0.26 & 0.14 & 0.11 & 0.03 \\
\hline \hline
\end{tabular}

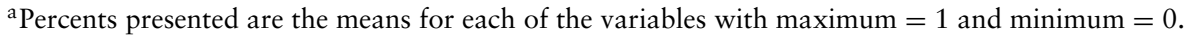

\section{Results and Discussion}

The four objectives for this work, models 1 through 4, are estimated in Stata (StataCorp, 2016). Results for the estimated impact of trade restrictions on U.S. exports are discussed in two categories: (1) average trade effects and (2) heterogeneous, commodity-level effects. This separation displays the variation around trade restrictions and how the average effects change when disaggregated to the commodity level.

\subsection{Average Trade Effects of Trade Restrictions}

Average trade effects for the trade restriction variables are presented in Table 4, which includes models 1 and 3. Both models present all poultry commodities in the analysis as aggregated products such that the effects of specific commodities are not explored. Model 1 presents a general trade restriction, in which any type of restriction is included in the indicator variable. Model 3 separates the trade restrictions into national-, state-, or county-level restrictions. For both models, 
Table 4. Average Trade Restriction Effects on Quantity Traded for General and Disaggregated Restriction Types during the 2014-2015 Highly Pathogenic Avian Influenza Event in U.S. Poultry (percentage)

\begin{tabular}{lll}
\hline \hline & $\begin{array}{l}\text { Model 1: Average } \\
\text { across All Products, } \\
\text { General Restriction }\end{array}$ & $\begin{array}{l}\text { Model 3: Average } \\
\text { across All Products, } \\
\text { Heterogeneous Types } \\
\text { of Restriction }\end{array}$ \\
\hline General poultry trade restriction & $-97.13^{* * *}$ & \\
National poultry trade restriction & $(0.09)$ & $-100.00^{* * *}$ \\
State poultry trade restriction & & $(0.15)$ \\
County poultry trade restriction & & $-28.82^{* * * *}$ \\
Observations & & $(0.11)$ \\
Number of ID & 13,159 & 20.92 \\
\hline \hline
\end{tabular}

Notes: Standard errors in parentheses. $* * P<0.01$; $* * P<0.05 ; * P<0.1$.

elasticities are presented after transformation using Halvorsen and Palmquist's (1980) equation (equation 6).

For model 1 , the average effect is a $97.13 \%$ reduction in bilateral trade for countries that impose any type of trade restriction. This implies that, on average across all commodities, an importing country that imposes trade restrictions effectively reduces trade to near zero units for all poultry trade with the United States. Although this is true for the countries that impose complete national restrictions, this may not be true for many countries that choose to have regionspecific or commodity-specific trade restrictions. General restrictions applied by importing countries that apply to the majority of poultry products traded, consequently skewing the overall effects, are a likely explanation for this drastic and significant estimated effect. This aggregate analysis provides a baseline to compare the heterogeneous effects of trade restrictions. Model 3 provides a deeper understanding of how the types of restrictions an importing country imposes affect quantity traded on average across all commodities.

Model 3 disaggregates the types of trade restrictions to account for the scope of the imposed trade restriction. Consistent with model 1, a national poultry trade restriction effectively closes all trade between the importing country and the United States with an estimated $100 \%$ reduction in trade. This reduction is expected, considering that trade partners imposing national-level poultry trade restrictions tended to impose restrictions across all poultry commodities, leading to drastic reduction of imports. For example, China and South Korea stopped all imports of all poultry and poultry products at the national level during the 2014-2015 U.S. HPAI event. 
State-level trade restrictions by were estimated, on average, to reduce trade by $28.82 \%$ for the 2014-2015 outbreak of HPAI. This implies that if a country is willing to regionalize restrictions for poultry products to the state level, allowing trade with the rest of the unaffected United States, the quantity traded will be reduced, but at one-third the magnitude of a national trade restriction. The importing country may be able to capture some excess supply as a result of complete national restrictions by other importing countries.

County-level trade restrictions did not significantly reduce the quantity traded between the United States and importing countries imposing the ban. This nonsignificant result suggests that importing countries who restrict products based on smaller disease-risk areas do not have a significant trade disruption. For an importing country, this can be beneficial in mitigating the impact of product disruptions in their own country, which can lead to processing disruptions and price impacts for consumers. For the United States, trading partners' willingness to regionalize trade restrictions to the affected county level can help to reduce one negative aspect of a highly pathogenic disease event.

\subsection{Heterogeneous, Commodity-Level Effects of Trade Restrictions}

The previous results focused on the average effects across poultry products. This section will focus on the implication of trade restrictions by commodity, offering a more detailed depiction of the effects importing country restrictions have on poultry commodity trade quantities. Table 5 presents results for models 2 and 4, heterogeneous, commodity-specific trade restrictions for general and geographically specific types of trade restrictions, respectively. Elasticities are presented after transformation using Halvorsen and Palmquist's (1980) equation (equation 6).

Model 2 estimates heterogeneous, commodity-specific effects of a general trade restriction. Analyzing these implications by commodity allows for more variation in the magnitude of trade reduction from the average analysis in model 1. Across the 14 commodities, the average effect on quantity traded for importing countries that imposed any type of trade restriction was a drastic reduction in commodity-specific quantity traded. For example, for live chicken-breeding stock, frozen chicken paws, frozen chicken legs, or frozen turkey legs, close to a $100 \%$ reduction was estimated. However, the impact on quantity traded still varied by commodity, even when general trade restrictions were applied. The quantity of frozen chicken wing tips traded was estimated on average to be reduced by $43.45 \%$ if any type of trade restriction was imposed. There are several products that have muted or no significant trade responses because of a trade restriction, such as feather meal, fresh turkey meat/edible offal, and frozen chicken meat. The lack of statistical significance implies that, given an importing country imposing a trade restriction on the product, the trade response does not statistically change. For example, prepared/preserved chicken meat did not have significant response. The lack of response can be explained in terms of 
Table 5. Results for Commodity-Specific Trade Restriction Effects for General and Disaggregated Restriction Type during 2014-2015 Highly Pathogenic Avian Influenza Event in U.S. Poultry

\begin{tabular}{|c|c|c|c|c|}
\hline & \multirow{2}{*}{$\begin{array}{l}\text { Model } 2 \\
\text { Commodity- } \\
\text { Specific, General } \\
\text { Trade } \\
\text { Restrictions }\end{array}$} & \multicolumn{3}{|c|}{ Model 4} \\
\hline & & $\begin{array}{l}\text { Commodity- } \\
\text { Specific, } \\
\text { National Trade } \\
\text { Restrictions }\end{array}$ & $\begin{array}{l}\text { Commodity- } \\
\text { Specific, } \\
\text { State Trade } \\
\text { Restrictions }\end{array}$ & $\begin{array}{l}\text { Commodity- } \\
\text { Specific, } \\
\text { County } \\
\text { Trade } \\
\text { Restrictions }\end{array}$ \\
\hline Frozen chicken leg quarters & $\begin{array}{l}-91.54 * * * \\
(0.22)\end{array}$ & $\begin{array}{l}-100.00 * * * \\
(0.37)\end{array}$ & $\begin{array}{l}24.61 \\
(0.24)\end{array}$ & $\begin{array}{l}-6.76 \\
(0.34)\end{array}$ \\
\hline Frozen chicken meat & $\begin{array}{l}-12.19 \\
(0.23)\end{array}$ & $\begin{array}{l}-84.43 * * * \\
(0.46)\end{array}$ & $\begin{array}{l}13.88 \\
(0.25)\end{array}$ & $\begin{array}{l}18.53 \\
(0.37)\end{array}$ \\
\hline Fresh chicken meat/edible offal & $\begin{array}{l}4.08 \\
(0.45)\end{array}$ & & $\begin{array}{l}-12.19 \\
(0.49)\end{array}$ & $\begin{array}{l}37.71 \\
(0.64)\end{array}$ \\
\hline Frozen chicken paws & $\begin{array}{l}-99.98 * * * \\
(0.33)\end{array}$ & $\begin{array}{l}-100.00 * * * \\
(0.4)\end{array}$ & $\begin{array}{l}-15.63 \\
(0.47)\end{array}$ & $\begin{array}{l}-39.35 \\
(0.64)\end{array}$ \\
\hline Frozen chicken legs & $\begin{array}{l}-98.62 * * * \\
(0.22)\end{array}$ & $\begin{array}{l}-100.00 * * * \\
(0.44)\end{array}$ & $\begin{array}{l}-89.97 * * * \\
(0.24)\end{array}$ & $\begin{array}{l}425.93 * * * \\
(0.36)\end{array}$ \\
\hline Fresh turkey meat/edible offal & $\begin{array}{l}-32.97 \\
(0.48)\end{array}$ & & $\begin{array}{l}-9.52 \\
(0.51)\end{array}$ & $\begin{array}{l}-40.55 \\
(0.61)\end{array}$ \\
\hline Feather meal & $\begin{array}{l}19.72 \\
(0.59)\end{array}$ & $\begin{array}{l}-78.99 \\
(1.12)\end{array}$ & $\begin{array}{l}9.42 \\
(0.76)\end{array}$ & $\begin{array}{l}153.45 \\
(1.07)\end{array}$ \\
\hline Frozen chicken wing tips & $\begin{array}{l}-43.45^{*} \\
(0.31)\end{array}$ & $\begin{array}{l}-99.97 * * * \\
(0.86)\end{array}$ & $\begin{array}{l}97.39 * * \\
(0.32)\end{array}$ & $\begin{array}{l}-69.27^{* *} \\
(0.47)\end{array}$ \\
\hline Fresh chicken eggs & $\begin{array}{l}99.37 \\
(0.83)\end{array}$ & & $\begin{array}{l}-18.94 \\
(1.55)\end{array}$ & $\begin{array}{l}197.43 \\
(1.73)\end{array}$ \\
\hline Live chicken-breeding stock & $\begin{array}{l}-100.00 * * * \\
(0.3)\end{array}$ & $\begin{array}{l}-100.00 * * * \\
(0.33)\end{array}$ & $\begin{array}{l}-16.47 \\
(0.5)\end{array}$ & $\begin{array}{l}3.92 \\
(0.65)\end{array}$ \\
\hline Prepared/preserved chicken meat & $\begin{array}{l}63.23 \\
(0.61)\end{array}$ & & $\begin{array}{l}50.68 \\
(0.66)\end{array}$ & $\begin{array}{l}13.88 \\
(0.79)\end{array}$ \\
\hline Frozen turkey meat & $\begin{array}{l}-91.87 * * * \\
(0.27)\end{array}$ & $\begin{array}{l}-100.00 * * * \\
(0.58)\end{array}$ & $\begin{array}{l}-23.66 \\
(0.31)\end{array}$ & $\begin{array}{l}-30.93 \\
(0.42)\end{array}$ \\
\hline Fresh whole chicken & $\begin{array}{l}-94.10 * * * \\
(0.58)\end{array}$ & $\begin{array}{l}-100.00 * * * \\
(1.06)\end{array}$ & $\begin{array}{l}-11.31 \\
(0.6)\end{array}$ & $\begin{array}{l}113.83 \\
(1.15)\end{array}$ \\
\hline Frozen turkey legs & $\begin{array}{l}-99.99 * * * \\
(0.32)\end{array}$ & $\begin{array}{l}-100.00 * * * \\
(0.37)\end{array}$ & $\begin{array}{l}-30.23 \\
(0.43)\end{array}$ & $\begin{array}{l}19.72 \\
(0.82)\end{array}$ \\
\hline Observations & 13,159 & & 13,159 & \\
\hline
\end{tabular}

the type of restriction imposed (discussed subsequently) or the fact that only $57 \%$ of importing countries imposing a trade restriction imposed a restriction on cooked products. Because properly handled and cooked poultry meat, even from HPAI-infected birds, is safe to eat, countries may exclude these products from their trade restrictions (Chmielewski and Swayne, 2011). In comparison, all importing countries imposing a trade restriction included frozen chicken legs and leg quarters, which had a near $100 \%$ reduction in trade. The countries that did impose some kind of trade restriction on prepared/preserved chicken meat 
may not have limited trade completely, leading to insignificant change in exports. For some products, there is a smaller group of target trading partners that may skew the estimated response by increasing trade in response to the changes in market price.

A limitation of model 2 is the aggregation of trade restriction types into one group. The aggregation provides a general impact of trade restrictions but does not differentiate by the type of trade restriction applied. Model 4 accounts for the geographic extent of trade restriction by commodity to estimate the effects of a national-, state-, and county-level trade restriction on quantity traded.

Differentiating the type of trade restriction and the commodity restricted offers the richest understanding of the impact of import trade restrictions on quantity traded. National-level restrictions are consistently estimated to reduce trade to the restricting importing country for every product except prepared/preserved chicken meat, fresh chicken meat/edible offal, and fresh turkey meat/edible offal, which could not be estimated because of too little variation within the panel. Quantities in frozen chicken meat traded are estimated to be reduced $84.43 \%$ given a national trade restriction. This might speak to minimal continued trade, delays in reporting, transportation lags, or limitations in recorded restrictions.

Trade restrictions that focus on smaller geographic areas are less likely to affect the quantity traded. For example, an importing country restriction of live chicken-breeding stock at the national level is estimated to reduce trade by $100 \%$. However, a state- or county-level trade restriction on the same product does not significantly affect the quantity traded. Those importing countries regionalizing trade restrictions at the state or county level may reduce imports from the restricted regions, but they may be able to maintain import quantities with products from the rest of the country. A similar relationship was found for many poultry commodities including frozen chicken paws, frozen chicken leg quarters, frozen turkey legs, frozen chicken meat, frozen turkey meat, and frozen chicken wing tips. These products all had no significant change in quantities traded from the United States when importing countries imposed either a state- or countylevel trade restriction. For these products that appear to be minimally affected, this can be driven by steady demand that can be fulfilled by the rest of the United States that is still able to trade.

Trade quantities for frozen chicken legs have a unique response to importing country restrictions. A national restriction is expected to decrease trade on average by $100 \%$, consistent with all other products. Similarly, a state-level restriction is estimated to result in a reduction of trade by $89.97 \%$ for the importing country. In the case of HPAI in U.S. poultry, trade quantities for frozen chicken legs are greatly reduced for importing countries imposing statelevel restrictions but to a lesser degree than a complete national restriction, implying that regionalization at the state level can reduce the bilateral trade disruption, on average, by $10.03 \%$ for trade-restricting importing countries, consistent with estimations by Johnson et al. (2014). On the contrary, a 
county-level trade restriction is expected to increase trade quantities imported from the United States by $425.93 \%$. The large change in trade is unique but not surprising. Some importing countries may benefit from reduced prices as a result of more restrictive importing country trade restrictions, increasing total trade quantities by countries willing to impose smaller regionalized trade restrictions. Dark chicken meat is often exported because of differences in tastes and preferences between U.S. consumers and importing markets. Restrictions by target export markets could lead to excess supply of these back ends, benefiting some importers.

Adoption of regionalized trade restrictions will continue to be an avenue to minimize trade disruptions as markets continue to become integrated globally. Collectively, these results across different commodities show a heterogeneous response that defines preference in demand and risk acceptance by importers. Importer views and willingness to regionalize are determined by many factors. Risk of disease spread and acceptance of these risks are scientifically, culturally, and politically informed. The use of regionalization can provide an avenue to limit disruptions of U.S. exports to the import markets. From a U.S. producer and processing standpoint, regionalization can help reduce the cost of an outbreak by providing market access and continued business during an outbreak like the 2014-2015 HPAI event studied here. In terms of government outlays, management of an outbreak can be costly to the responding country, and these results provide a justification for the cost and implementation of regulation and permitting schemes that provide reassurances to importing countries of the disease-free status of U.S. product not included in the restricted region.

\section{Conclusion}

Trade partners may choose to restrict trade during a disease event in an exporting country. Importing countries decide what products should be included in the restriction, the geographic extent of the restriction, and the length of the restriction. Trade partners may choose to regionalize by limiting trade restrictions geographically during a disease event, which can greatly affect the consequences of the disease event for all parties involved. Using the 2014-2015 HPAI event in U.S. poultry to study trade consequences, this work shows that regionalized trade restrictions at the state and county level can mitigate negative trade impacts and ease some of the cost typically associated with high infectious disease events in animal agriculture. As expected, a national trade restriction tended to effectively reduce trade by $100 \%$ for the trade-restricting importing country. More importantly, when importing countries limited restrictions to the state level, the average reduction in trade was $29 \%$. County-level restrictions showed no significant changes in trade quantities for the restricting trade partner, as this allowed for continued trade and potential capture of supply typically destined for more restrictive importers. These results indicate that the more compact the 
region in which trade restrictions are applied, the greater the potential mitigation of the losses associated with an HPAI event.

The specific trade implications presented in this work center around HPAI trade, but broader inferences may be drawn for application to other animal health events such as FMD, BSE, or porcine epidemic diarrhea virus outbreaks. Although industry factors affect the risk perception and willingness to accept product, this work shows potential willingness in a globalized trading environment for mitigation of supply disruptions as a result of disease events. The basis for the analyses presented includes the observed and recorded trade restrictions by geographic extent across product groups and for specific commodities. Applying similar trade restriction regionalization in other livestock industries, it may be possible to see similar trade effects with the possibility of reduction in the overall cost to exporter and importers during a disease event. The use of regionalization by trade-restricting countries can provide greater resilience in bilateral trade relationships given that the exporter can continue to show disease-free status in the exporting region.

This work provides a unique estimation of actual product restrictions on trade quantities. It is limited by the species of animals affected and geographic location of the disease event. Future research may extend the scope of this work to broader implications of animal disease trade impacts by recording and estimating the effects across different animal species and disease events. Similarly, dynamic analyses of the changes in quantity traded as the outbreak progresses could show not only heterogeneity between commodities but also the time effects of a disease outbreak. Although U.S. exports are the focus of this work, a future extension could compare the trade effects in the United States to other exporting countries experiencing HPAI in 2016 and estimate the global impacts of trade restrictions because of animal health events. Although there are no formal repositories for trade restrictions, this work has shown the value that recording trade restrictions can provide in estimating the impacts of importing country trade restrictions.

\section{References}

Anderson, J.E. “The Gravity Model." National Bureau of Economic Research (NBER) Working Paper No. W16576, Cambridge, MA: NBER, 2010.

Anderson, J.E., and E. van Wincoop. "Gravity with Gravitas: A Solution to the Border Puzzle." American Economic Review 93,1(2003):170-92.

Baier, S.L., and J.H. Bergstrand. "Do Free Trade Agreements Actually Increase Members' International Trade?” Journal of International Economics 71,1(2007):72-95.

Baltagi, B., P. Egger, and M. Pfaffermayr. "Panel Data Gravity Models of International Trade." Center for Economic Studies and Ifo Institute for Economic Research (CESifo) Working Paper No. 4616, Munich, Germany: CESifo, Munich University, 2014.

Baltagi, B.H., G. Bresson, and A. Pirotte. "Fixed Effects, Random Effects or Hausman-Taylor? A pretest estimator.” Economics Letters 79,3(2003):361-69. 
Bergstrand, J.H. "The Gravity Equation in International Trade: Some Microeconomic Foundations and Empirical Evidence." Review of Economics and Statistics 67,3(1985):474-81.

Brent, D.A. "The Value of Heterogeneous Property Rights and the Costs of Water Volatility." American Journal of Agricultural Economics 99,1(2017):73-102.

Breusch, T.S., and A.R. Pagan. "The Lagrange Multiplier Test and Its Applications to Model Specification in Econometrics." Review of Economic Studies 47,1(1980):239-53.

Burger, M., F. van Oort, and G.-J. Linders. "On the Specification of the Gravity Model of Trade: Zeros, Excess Zeros and Zero-inflated Estimation.” Spatial Economic Analysis 4,2(2009):167-90.

Chaney, T. "The Gravity Equation in International Trade: An Explanation.” National Bureau of Economic Research (NBER) Working Paper No. 19285, Cambridge, MA: NBER, 2013.

Chmielewski, R., and D.E. Swayne. "Avian Influenza: Public Health and Food Safety Concerns." Annual Review of Food Science and Technology 2(April 2011):37-57.

Costa, R., D. Bessler, and C.P. Rosson. "The Impacts of Foot and Mouth Disease Outbreaks on the Brazilian Meat Market." Journal of Food Distribution Research 46,3(2015):1-19.

Egger, P., and M. Pfaffermayr. "Distance, Trade and FDI: A Hausman-Taylor SUR Approach." Journal of Applied Econometrics 19,2(2004):227-46.

Halvorsen, R., and R. Palmquist. "The Interpretation of Dummy Variables in Semilogarithmic Equations.” American Economic Review 70,3(1980):474-75.

Hausman, J.A. "Specification Tests in Econometrics." Econometrica 46,6(1978):1251-71.

Hausman, J.A., and W.E. Taylor. "Panel Data and Unobservable Individual Effects." Econometrica 49,6(1981):1377-98.

Huang, W., A. Hagerman, and D.A. Bessler. "The Impact of Highly Pathogenic Avian Influenza on Table Egg Prices." Choices 31,2(2016):1-7.

Isard, W. "Location Theory and Trade: Short-Run Analysis." Quarterly Journal of Economics 68,2(1954):305-20.

Johnson, K., A. Hagerman, J. Thompson, and C. Kopral. "Factors Influencing Export Value Recovery after Highly Pathogenic Poultry Disease Outbreaks." International Food and Agribusiness Management Review 18, Special Issue A(2015):27-42.

Johnson, K., P.L. Paarlberg, A.H. Seitzinger, S. Ott, and D. Anderson. Analysis of Hypothetical Highly Pathogenic Avian Influenza Outbreak in Texas on the Supply Chain. Lakewood, CO: Livestock Marketing Information Center, 2014.

Koo, W.W., D. Karemera, and R. Taylor. “A Gravity Model Analysis of Meat Trade Policies.” Agricultural Economics 10,1(1994):81-88.

Martínez-Zarzoso, I., and F. Nowak-Lehmann. "Augmented Gravity Model: An Empirical Application to Mercosur-European Union Trade Flows." Journal of Applied Economics 6,2(2003):291-316.

Paarlberg, P.L., and J.G. Lee. "Import Restrictions in the Presence of a Health Risk: An Illustration Using FMD.” American Journal of Agricultural Economics 80,1(1998):17583.

Paarlberg, P.L., A.H. Seitzinger, and J.G. Lee. "Economic Impacts of Regionalization of a Highly Pathogenic Avian Influenza Outbreak in the United States." Journal of Agricultural and Applied Economics 39,2(2007):325-33.

Paarlberg, P.L., A.H. Seitzinger, J.G. Lee, and K.H. Mathews. "Supply Reductions, Export Restrictions, and Expectations for Hog Returns in a Potential Classical Swine Fever Outbreak in the United States." Journal of Swine Health and Production 17,3(2009):155-62. 
Pendell, D.L., J. Leatherman, T.C. Schroeder, and G.S. Alward. "The Economic Impacts of a Foot-and-Mouth Disease Outbreak: A Regional Analysis." Journal of Agricultural and Applied Economics 39,S1(2007):19-33.

Ruhl, K.J. “Trade Dynamics under Policy Uncertainty.” American Journal of Agricultural Economics 93,2(2011):450-56.

Seitzinger, A.H., and P.L. Paarlberg. "Regionalization of the 2014 and 2015 Highly Pathogenic Avian Influenza Outbreaks.” Choices 31,2(2016):1-8.

Serlenga, L., and Y. Shin. "Gravity Models of Intra-EU Trade: Application of the CCEP-HT Estimation in Heterogeneous Panels with Unobserved Common Time-Specific Factors.” Journal of Applied Econometrics 22,2(2007):361-81.

StataCorp. Stata: Statistics/Data Analysis. College Station, TX: StataCorp, 2016.

Sun, L., and M.R. Reed. "Impacts of Free Trade Agreements on Agricultural Trade Creation and Trade Diversion.” American Journal of Agricultural Economics 92,5(2010):135163.

Thompson, J.M., and D.L. Pendell. "Proactive Risk Assessments to Improve Business Continuity." Choices 31,2(2016):1-8.

Tinbergen, J. Shaping the World Economy: Suggestions for an International Economic Policy. New York: Twentieth Century Fund, 1962.

U.S. Department of Agriculture, Animal and Plant Health Inspection Service (USDA-APHIS). HPAI Outbreak 2014-2015: Control Area Release. Riverdale, MD: USDA-APHIS, $2015 \mathrm{a}$.

— 2016 HPAI Preparedness and Response Plan. Riverdale, MD: USDA-APHIS, 2016.

- Avian Influenza Disease. Riverdale, MD: USDA-APHIS, 2015b.

U.S. Department of Agriculture, Office of the Chief Economist (USDA-OCE). World Agricultural Supply and Demand Estimates Report (WASDE). Washington, DC: USDAOCE, 2016.

Vollrath, T., and C. Hallahan. Reciprocal Trade Agreements: Impacts on Bilateral Trade Expansion and Contraction in the World Agricultural Marketplace. Washington, DC: U.S. Department of Agriculture, Economic Research Service, Economic Research Report No. 113, 2011.

Wilson, N.L.W., and J. Antón. "Combining Risk Assessment and Economics in Managing a Sanitary-Phytosanitary Risk.” American Journal of Agricultural Economics 88,1(2006):194-202. 